\title{
High-velocity frictional behavior of Longmenshan fault gouge from Hongkou outcrop and its implications for dynamic weakening of fault during the 2008 Wenchuan earthquake*
}

\author{
Tetsuhiro Togo ${ }^{1, *}$ Toshihiko Shimamoto ${ }^{2}$ \\ Shengli $\mathrm{Ma}^{2}$ and Takehiro Hirose ${ }^{3}$ \\ 1 Department of Earth and Planetary Systems Science, Graduate School of Science, \\ Hiroshima University, Higashi-Hiroshima, 739-8526, Japan \\ ${ }^{2}$ State Key Laboratory of Earthquake Dynamics, Institute of Geology, China Earthquake \\ Administration, Beijing 100029, China \\ ${ }^{3}$ Kochi Institute for Core Sample Research, Japan Agency for Marine-Earth Science and \\ Technology (JAMSTEC), 200 Monobe-otsu, Kochi 783-8502, Japan
}

\begin{abstract}
High-velocity friction experiments were conducted on clayey fault gouge collected from Hongkou outcrop of Beichuan fault, located at the southwestern part of Longmenshan fault system that caused the disastrous 2008 Wenchuan earthquake. The ultimate purpose of this study is to reproduce this earthquake by modeling based on measured frictional properties. Dry gouge of about $1 \mathrm{~mm}$ in thickness was deformed dry at slip rates of 0.01 to $1.3 \mathrm{~m} / \mathrm{s}$ and at normal stresses of 0.61 to $3.04 \mathrm{MPa}$, using a rotary-shear high-velocity frictional testing machine. The gouge displays slip weakening behavior as initial peak friction decays towards steady-state values after a given displacement. Both peak friction and steady-state friction remain high at slow slip rates are examined and gouge only exhibits dramatic weakening at high slip rates, with steady-state friction coefficient values of about 0.1 to 0.2 . Specific fracture energy ranges from 1 to $4 \mathrm{MN} / \mathrm{m}$ in our results and this is of the same order as seismically determined values. Low friction coefficients measured on experimental faults are in broad agreement with lack of thermal anomaly observed from temperature measurements in WFSD-1 drill hole (Wenchuan Earthquake Fault Scientific Drilling Project), which can be explained by even smaller friction coefficient for the Wenchuan earthquake fault. High-velocity friction experiments with pore water needs to be done to see if even smaller friction is attained or not. Shiny slickenside surfaces form at high slip rates, but not at slow slip rates. Slip zone with slickenside surface changes its color to dark brown and forms duplex-like microstructures, which are similar to those microstructures found in the fault gouges from the Hongkou outcrop. Detailed comparisons between experimentally deformed gouge samples and WFSD drill cores in the future will reveal how much we could reproduce the dynamic weakening processes in operation in fault zones during Wenchuan earthquake at present.
\end{abstract}

Key words: Wenchuan earthquake; high-velocity friction; fault mechanics; Longmenshan fault system; Beichuan fault

CLC number: P315.8 Document code: A

\section{Introduction}

Large earthquakes can be more realistically

\footnotetext{
* Received 25 January 2011; accepted in revised form 6 April 2011; published 10 June 2011.

* Corresponding author. e-mail: duketogotetsu@gmail.com

(C) The Seismological Society of China and Springer-Verlag Berlin Heidelberg 2011
}

modeled by using measured mechanical and transport properties of fault rock samples collected from fault zones which hosted an earthquake. The 2008 Wenchuan earthquake (12 May 2008, $M_{\mathrm{W}} 7.9$ ) is an ideal target for collecting good quality data for such integrated mechanical and seismological studies since current drilling into the fault zones and many fault outcrops along Longmen- 
shan fault system, that caused the destructive earthquake, will allow the collection of fault rocks which have recently experienced seismic rupture propagation. As part of a comprehensive project on this fault system, we have analyzed internal structures of Beichuan fault zone at Hongkou outcrop (Togo et al., 2011). The present paper reports results from high-velocity friction experiments on fault gouge collected from this outcrop, trying to reproduce seismic fault motion during Wenchuan earthquake in laboratory.

Verberne et al. (2010) conducted friction experiments at slow slip rates on fault gouge collected from the same outcrop and on protolith sedimentary rocks, using a gas apparatus. They recognized velocity strengthening properties, i.e., higher friction at higher velocities, and argued that clay-rich sediments may have damping effect on the earthquake rupture as it propagates upward. After the nucleation of an earthquake, rupture propagation along a fault will occur at seismic slip rates, typically on the order of $1 \mathrm{~m} / \mathrm{s}$. Thus frictional properties at slow slip rates are relevant to control the nucleation of an earthquake, but high-velocity frictional properties are those controlling the propagation of a rupture in portions of the fault away from the nucleation zone. Driven by these motivations, we conducted highvelocity friction experiments on incohesive fault gouges, collected along the fault at Hongkou outcrop, which are representative of fault rocks formed at shallow depths near the western end of Longmenshan fault system.

High-velocity friction of faults (i.e., frictional properties of faults at high slip rates and large displacements) has been one of the most debated issues in fault mechanics in the last two decades. There have been important progress in the understanding of coseismic processes such as: (1) frictional melting (e.g., Hirose and Shimamoto, 2005; Di Toro et al., 2006; Nielsen et al., 2008), (2) thermal pressurization (see Sibson, 1973; Lachenbruch, 1980; Mase and Smith, 1987; Wibberley and Shimamoto, 2005; Noda and Shimamoto, 2005; Rice, 2006) and (3) fault gouge behavior at high-velocities (Mizoguchi et al., 2007, 2009; Han et al., 2007a, b; De Paola et al., 2011; Brantut et al., 2011; among others). Since rotary-shear high-velocity friction apparatus were introduced in earth science community in late 1980's (Spray, 1987) and in early 1990's (Shimamoto and Tsutsumi, 1994), high-velocity experiments have been conducted on the topics (1) and (3) above. Whereas topic (2) has been only studied from a theoretical point of view, based on measured transport properties (permeability and specific storage capacity) of fault zones. Nearly all studies have revealed dramatic weakening of faults with frictional coefficients on the order of 0.05 to 0.3 at high velocities.

In this paper, we focus on fault gouge behavior at constant slip rates without frictional melting because pseudotachylites are rare within large-scale incohesive fault zones and massive pseudotachylites are not reported in Longmenshan fault system. Local pseudotachylites may be reported in the future, but very local frictional melting cannot dictate the gross fault properties. Thermal pressurization requires measurements of permeability and specific storage capacity and this is beyond the scope of this paper. However, our highvelocity friction specifies heat source in thermal pressurization analysis. Seismogenic fault motion does not occur at constant slip rates (e.g., Tinti et al., 2005). Sone and Shimamoto (2009) have shown that accelerating/decelerating slip history yields different features in fault properties. However, constant slip-rate tests can still be a basis for characterizing high-velocity frictional properties and can yield parameters which will be useful for describing friction behavior with variable slip histories. Fault behaviors under variable slip histories are currently under investigation and the results will be reported elsewhere.

Present work has at least three scientific scopes. Firstly, temperature measurements have been conducted in Wenchuan Earthquake Fault Scientific Drilling (WFSD) Project trying to detect small temperature anomaly and thereby to determine the level of friction along coseismic fault during Wenchuan earthquake. Two sets of temperature measurements in WFSD-1 hole revealed a very small temperature anomaly (less than 0.05 degrees centigrade), corresponding to frictional coefficient well below 0.1 (Mori et al., 2010; Li et al., 2010b). How close to these estimated values can laboratory experiments yield is an interesting and important scientific issue, since this borehole was drilled only several hundred of meters north of the Hongkou outcrop, where we collected gouge samples for laboratory tests. Secondly, black gouge with anomalous clay mineralogy and high magnetic susceptibility is reported from WFSD-1 drill hole at a depth of about $590 \mathrm{~m}$, which is the strongest candidate of coseismic fault ( $\mathrm{Li}$ et al., 2010a; Si et al., 2010). Similar fault gouge was not found at Hongkou outcrop (Togo et al., 2011). However, highvelocity friction experiments could show if such fault rocks can form during seismogenic fault motion or not. Thirdly, our results can be compared with results from similar experiments on WFSD drill cores in the future to 
see if surface samples can yield similar results to those from drill cores or not (or to evaluate the effect of weathering). Permeability structure of Nojima fault zone, as measured on surface samples (Mizoguchi et al., 2008), agrees reasonably well with that determined from drill cores (Lockner et al., 2009). It is extremely important to evaluate if surface samples can be used to infer the fault properties at depths since physical properties are measured on surface samples in majority of cases. WFSD provides an excellent chance for such testing.

\section{Experimental procedures}

Figure 1 shows the first high-velocity frictional testing machine used in our high velocity friction experiments (see Shimamoto and Tsutsumi, 1994; Hirose and Shimamoto, 2005). It is a simple machine in which an axial force up to $10 \mathrm{kN}$ is applied to a set of hollowor solid-cylindrical specimens of $25-40 \mathrm{~mm}$ in diameter using an air actuator (bellow cylinder), and a 7.5 $\mathrm{kW}$ motor is used to rotate one side of the specimen at revolution rates to $1500 \mathrm{rpm}$. A spline prevents ro- tation of the stationary specimen. Torque is measured with a combined torque/axial force gauge set next to the stationary side of the specimen. Axial force to determine normal stress on the specimen is also measured with a force gauge set between the air actuator and spline. The outputs for axial force from this gauge and the torque/axial force gauge are nearly identical, indicating that ball-bearing friction in spline is negligibly small. We use output from the latter for normal stress measurement. Axial displacement is measured with a displacement transducer set near axial force gauge. In conducting experiments, axial force is applied to specimens first, motor is turned on and wait for the motor to reach a set-up speed, and then an electromagnetic clutch is turned on to start a run. One problem in our experiments is that the axial force changes during experiments by plus/minus about $5 \%$ during a run primarily because the loading piston does not move smoothly due to O-ring friction. We calculated frictional coefficient from measured shear stress and normal stress at a given time, unless otherwise specified.

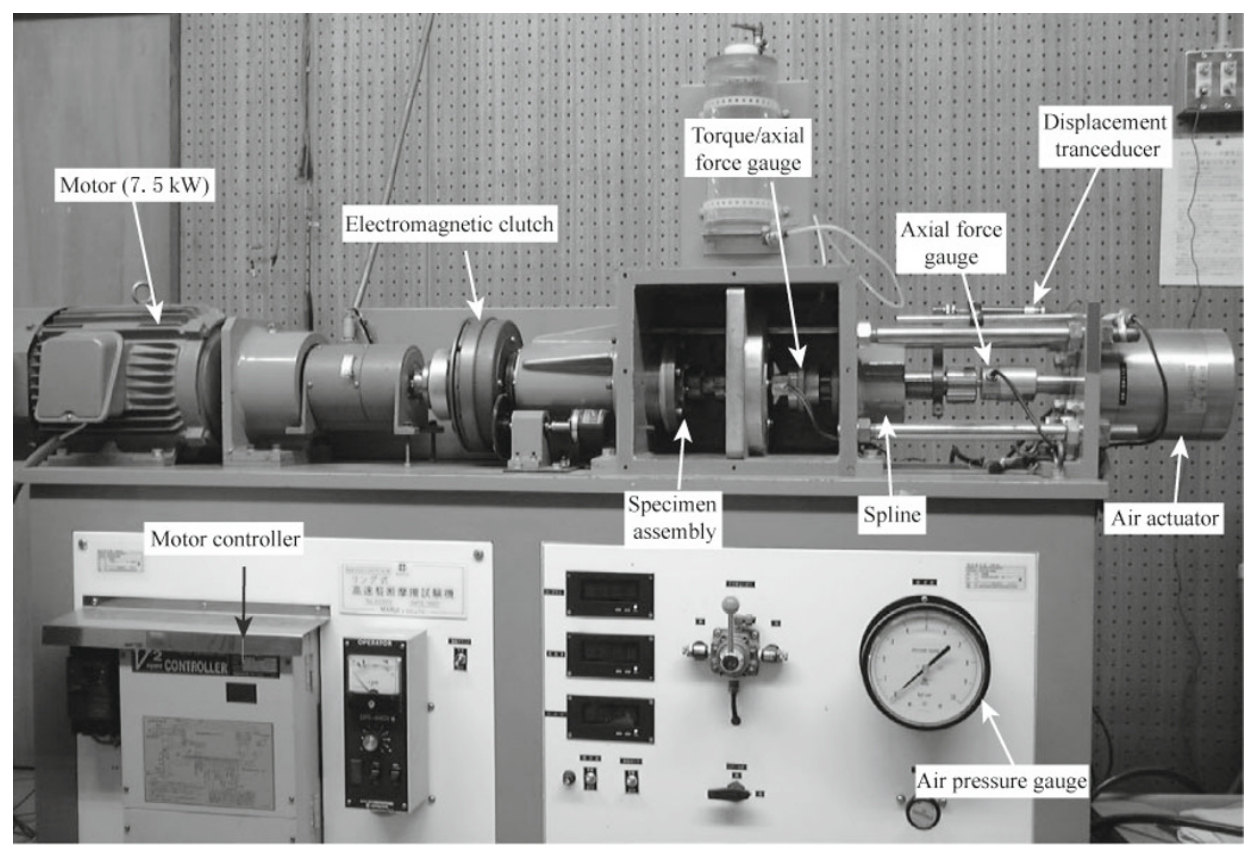

Figure 1 A rotary-shear high-velocity frictional testing machine, now at Kochi Institute for Core Sample Research, Japan Agency for Marine-Earth Science and Technology (JAMSTEC). The machine was built by Marui Co. Ltd., Osaka, Japan, and was installed in Earthquake Research Institute, University of Tokyo in 1990.

A disadvantage of any rotary-shear apparatus is a large displacement gradient from the center to the margin of a specimen. Shimamoto and Tsutsumi (1994) defined "equivalent slip rate" such that shear stress $(\tau) \times$ equivalent slip rate $\left(v_{\mathrm{eq}}\right) \times$ fault area $(S)$ gives rate of frictional work over the fault surface. Shear stress is assumed to be independent of slip rates across the specimen in the definition. Equivalent slip or equivalent dis- 
placement, $d_{\mathrm{eq}}$, can be defined in a similar manner such that $\tau \cdot d_{\text {eq }} \cdot S$ gives the frictional work over the fault surface. The frictional works and its rate can be calculated without integration using $v_{\text {eq }}$ and $d_{\text {eq }}$, respectively. Hereafter $v_{\text {eq }}$ and $d_{\text {eq }}$ are called velocity (or slip rate) and displacement (or slip), respectively.

We used solid cylindrical specimen of Belfast dolerite of $25 \mathrm{~mm}$ in diameter as host rock to hold gouge (Figure 2). Following Mizoguchi et al. (2007), we used Teflon sleeve outside to hold the gouge. The inner diameter of the Teflon sleeve is made smaller than the outer diameter of the dolerite cylinder by $0.1 \mathrm{~mm}$ to impose a small seal pressure preventing the gouge loss. Correction for friction between a Teflon sleeve and specimen assembly is explained in the next section. Host rock is unconfined and becomes very weak due to thermal fracturing from frictional heating. Belfast gabbro is one of the strongest rocks among many rocks we tested, is available commercially in many countries and is selected for our study. The dolerite specimens were shaped with diamond wheels using cylindrical and surface grinders, and their sliding surfaces were roughed by grinding with \#80 SiC powder on a glass plate by hands. It is better to use hollow cylindrical specimens as used in rock-onrock friction experiments with the same machine (e.g., Tsutsumi and Shimamoto, 1997; Hirose and Shimamoto, 2005) to reduce the gradient in slip rate. However, conducting high-velocity gouge experiments with hollow cylindrical specimen is still very difficult technically. A simple calculation can show that the shear resistance in outer part of a cylindrical specimen reflects far more on measured torque. The first high-velocity machine is capable of producing slip rates of a few $\mathrm{mm} / \mathrm{s}$ to 1.3 $\mathrm{m} / \mathrm{s}$ for solid cylindrical specimens of $25 \mathrm{~mm}$ in diameter used in our experiments. Thus, seismic slip rate can be produced in laboratory.
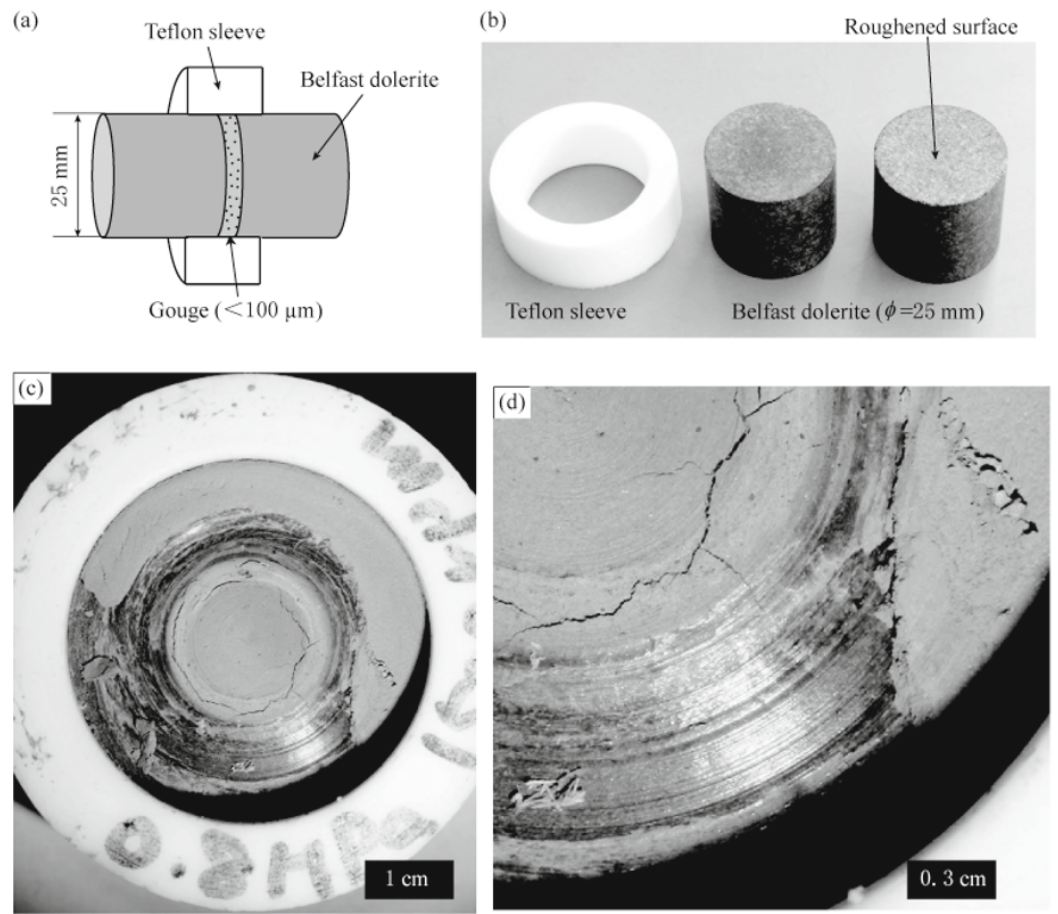

Figure 2 (a) A schematic diagram of the specimen assembly for high-velocity experiments on fault gouge sample. (b) A Photograph of a Teflon sleeve and cylindrical specimens of Belfast dolerite as host rock (25 mm in diameter). (c) A photograph of Longmenshan fault gouge deformed dry at a normal stress of $0.8 \mathrm{MPa}$ and at a slip rate of $1.3 \mathrm{~m} / \mathrm{s}$ after the moving side of host rock is removed. Shiny slickenside surface is developed well in outer half of the gouge sample and can be seen in the lower-left side, whereas slickenside surface is hidden in less deformed gouge in the upper-right side. (d) A close-up photograph of the slickenside surface in (c).

\section{Experimental results}

Fault gouge was collected from Hongkou outcrop of Beichuan fault on the western part of the Longmen- shan fault system (Togo et al., 2011). The hanging-wall side of the Beichuan fault zone consists of fault breccia zone of $30-40 \mathrm{~m}$ in width and of weakly foliated clayey fault gouge of about $1 \mathrm{~m}$ thick next to the coseismic fault 
during the 2008 Wenchuan earthquake. Gouge sample used in experiments was collected from the gouge zone about $10 \mathrm{~cm}$ from the edge of gouge zone (shown as gouge 1 in Figure 5a of Togo et al., 2011). This gouge contains illite and chlorite as clay minerals, but not smectite. One gram of dry gouge was placed between a pair of solid cylindrical specimens of Belfast dolerite (gouge thickness is about $1 \mathrm{~mm}$ when porosity reduces to about $20 \%$ ).

Figure 2c shows a representative gouge specimen deformed dry at a normal stress of $0.8 \mathrm{MPa}$ and at a slip rate of $1.3 \mathrm{~m} / \mathrm{s}$. A very shiny slickenside surface is developed within gouge close to its interface to the moving host rock and this can be seen in the lower-left side of Figure 2c (see its close-up in Figure 2d). The gouge-host rock interface was separated in the upperright side, whereas the gouge was separated across the slickenside surface in the lower-left side when the host on the moving side was removed carefully not to damage the gouge severely. A shiny slickenside surface can be seen on the lower-left side, but the slickenside surface is hidden underneath a very-thin less-deformed gouge there (Figure 2c). The central portion of gouge retains its original greyish color because of less frictional heating in the center.

Figure 3a shows representative results showing frictional coefficient plotted against fault displacement for gouge samples deformed dry at a normal stress of 1.0 $\mathrm{MPa}$ and at eight different slip rates as shown in the diagram. At the highest slip rate of $1.3 \mathrm{~m} / \mathrm{s}$, the peak friction of 0.72 is followed by marked slip weakening toward nearly steady-state friction of about 0.132 . The peak friction remains high for all slip rates, but the steady-state friction decreases with increasing slip rate. Figure 3b displays intermediate to high-velocity behavior of seven gouge samples deformed dry at a slip rate of $1.3 \mathrm{~m} / \mathrm{s}$ and at a normal stress ranging from 0.61 to 3.04 $\mathrm{MPa}$ as shown in the diagram. In all cases faults weaken towards steady-state frictional coefficient of 0.06 to 0.16 , and the higher the normal stress, the more rapidly the gouges weaken with slip.

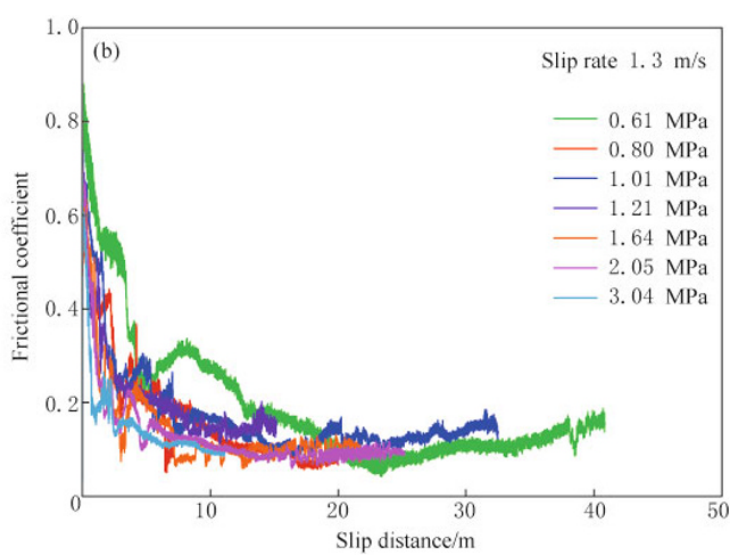

Figure 3 Evolutions of frictional coefficient with an increasing displacement. (a) The experiments were conducted at a normal stress of $1.0 \mathrm{MPa}$ and slip rates were changed from $0.01 \mathrm{~m} / \mathrm{s}$ to $1.30 \mathrm{~m} / \mathrm{s}$. (b) The experiments were conducted at a slip rates of $1.3 \mathrm{~m} / \mathrm{s}$ and normal stresses were changed from $0.61 \mathrm{MPa}$ to $3.04 \mathrm{MPa}$. Shear stress is corrected for Teflon friction.

The post-peak slip weakening can be described by an empirical equation used in Mizoguchi et al. (2007):

$$
\mu(d)=\mu_{\mathrm{ss}}+\left(\mu_{\mathrm{p}}-\mu_{\mathrm{ss}}\right) \exp \left(\ln 0.05 d / D_{\mathrm{c}}\right),
$$

where $\mu$ is the frictional coefficient, $\mu_{\mathrm{p}}$ is the peak friction, $\mu_{\mathrm{ss}}$ is the steady-state friction, $d$ is displacement after the peak friction, and $D_{\mathrm{c}}$ is the slip-weakening distance, defined as the displacement corresponding to the $95 \%$ reduction from $\mu_{\mathrm{p}}$ to $\mu_{\mathrm{ss}}$. The slip weakening distance is normally defined as the displacement required for friction to drop from $\mu_{\mathrm{p}}$ to $\mu_{\mathrm{ss}}$. However, such a distance is infinite for an exponential decay in (1), so we conventionally use $D_{\text {c }}$ for $95 \%$ reduction. Note that $\exp \left(\ln 0.05 d / D_{\mathrm{c}}\right)=0.05$ when $d=D_{\mathrm{c}}$ in equation (1). A solid line in Figure 4 is a least-squares best-fit of equation (1) to a representative result, and the result shows that the empirical equation fits experimental results reasonably well. Table 1 gives a list of experiments, experimental conditions and parameters in equation (1). Friction tends to increase slightly with increasing 


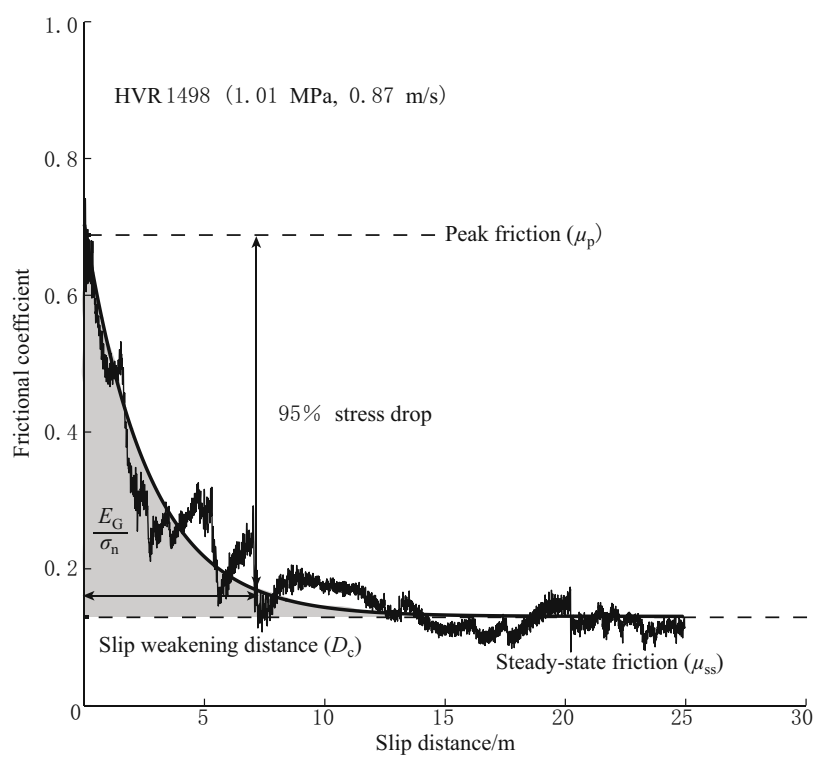

Figure 4 Frictional coefficient versus displacement curve for gouge deformed at a normal stress of $1.01 \mathrm{MPa}$ and at a slip rate of $0.87 \mathrm{~m} / \mathrm{s}$ (solid line). A thick solid line is the least squares fit to the experimental data with equation (1). Peak friction $\mu_{\mathrm{p}}$ is read from experimental data as 0.72 , and slip weakening distance $D_{\mathrm{c}}$ and steadystate friction $\mu_{\mathrm{ss}}$ are determined as $8.9 \mathrm{~m}$ and 0.125 , respectively, using Kaleidagraph software.

displacement near the end of experiments shown in Figure $3 \mathrm{~b}$. This could be due to drying of gouge by frictional heating, but we did not take it into account in our fitting and simply used equation (1) in the fitting.

Figure 5 shows shear stress plotted against normal stress for seven gouge samples deformed dry at a slip rate of $1.3 \mathrm{~m} / \mathrm{s}$ (peak friction in circle and steady-state friction in square). By definition, peak friction coefficient can be determined from the maximum shear stress divided by the normal stress at that point. In practice, however, shear stress and normal stress fluctuate at each revolution of specimen due to slight misalignmen$\mathrm{t}$ of the specimen and loading column. The fluctuation in shear stress is about $5 \%$ and we took averages for shear stress and normal stress over the range from the maximum shear stress $\tau_{\max }$ down to $0.95 \tau_{\max }$. Those averaged shear stress and normal stress near the peak friction are plotted as open circles in Figure 5. Identifying steady-state point on the curves in Figure 3 is not easy. Thus we considered that nearly steady-state is attained when displacement reached $D_{\mathrm{c}}$ value in equation (1), and then plotted averages of measured shear stress and normal stress at displacements greater than $D_{\mathrm{c}}$ in Figure 5. Shear stress increases linearly with increasing normal stress for both peak and steady-state friction. Thus Coulomb's law of friction holds except for small intercepts from origin ( $0.113 \mathrm{MPa}$ for peak friction and $0.069 \mathrm{MPa}$ for steady-state friction). This intercept is of about the same as Teflon friction and has been interpreted as due to friction between the Teflon sleeve and a specimen assembly (Mizoguchi et al., 2007; see also Sone and Shimamoto, 2009, supplementary online information). We also consider the intercepts as due to Teflon friction.

A simple way of correcting Teflon friction is to reduce a constant value (e.g., average of the two intercepts in Figure 5) from measured shear stress. However, the subtraction of a constant will cause negative shear

Table 1 Experimental conditions and related parameters for the experiments in this study

\begin{tabular}{|c|c|c|c|c|c|c|c|c|}
\hline $\begin{array}{c}\text { Experiment } \\
\text { number }\end{array}$ & $\begin{array}{l}\text { Normal } \\
\text { stress } \\
/ \mathrm{MPa}\end{array}$ & $\begin{array}{l}\text { Slip rate } \\
/\left(\mathrm{m} \cdot \mathrm{s}^{-1}\right)\end{array}$ & $\mu_{\mathrm{p}}$ & $\mu_{\mathrm{ss}}$ & $\begin{array}{c}\tau_{\mathrm{p}} \\
/ \mathrm{MPa}\end{array}$ & $\begin{array}{c}\tau_{\mathrm{ss}} \\
/ \mathrm{MPa}\end{array}$ & $\begin{array}{l}D_{\mathrm{c}} \\
/ \mathrm{m}\end{array}$ & $\begin{array}{l}\text { Normalized } \\
\text { fracture energy } \\
\quad /\left(\mathrm{MN} \cdot \mathrm{m}^{-1}\right)\end{array}$ \\
\hline HVR1489 & 1.01 & 1.30 & 0.72 & 0.13 & 0.67 & 0.14 & 0.69 & 1.20 \\
\hline HVR1490 & 0.80 & 1.30 & 0.69 & 0.06 & 0.50 & 0.01 & 9.74 & 1.60 \\
\hline HVR1491 & 0.61 & 1.30 & 0.87 & 0.12 & 0.45 & 0.08 & 12.40 & 1.83 \\
\hline HVR1494 & 1.21 & 1.30 & 0.62 & 0.16 & 0.67 & 0.20 & 4.53 & 0.84 \\
\hline HVR1496 & 1.64 & 1.30 & 0.63 & 0.10 & 1.01 & 0.18 & 4.87 & 1.30 \\
\hline HVR1497 & 2.05 & 1.30 & 0.69 & 0.10 & 1.34 & 0.22 & 3.65 & 1.35 \\
\hline HVR1498 & 1.01 & 0.87 & 0.72 & 0.13 & 0.77 & 0.12 & 8.90 & 2.35 \\
\hline HVR1499 & 1.01 & 0.43 & 0.69 & 0.30 & 0.75 & 0.26 & 13.76 & 1.94 \\
\hline HVR1500 & 1.04 & 0.09 & $\mathrm{~N} / \mathrm{A}$ & 0.73 & $\mathrm{~N} / \mathrm{A}$ & 0.70 & $\mathrm{~N} / \mathrm{A}$ & $\mathrm{N} / \mathrm{A}$ \\
\hline HVR1501 & 1.01 & 0.01 & $\mathrm{~N} / \mathrm{A}$ & 0.74 & $\mathrm{~N} / \mathrm{A}$ & 0.68 & $\mathrm{~N} / \mathrm{A}$ & $\mathrm{N} / \mathrm{A}$ \\
\hline HVR1502 & 3.04 & 1.30 & 0.67 & 0.12 & 1.94 & 0.37 & 1.88 & 1.04 \\
\hline HVR1624 & 1.03 & 1.08 & 0.88 & 0.18 & 0.92 & 0.11 & 6.99 & 1.69 \\
\hline HVR1625 & 1.02 & 0.59 & 0.89 & 0.28 & 0.86 & 0.14 & 13.13 & 4.78 \\
\hline HVR1626 & 1.03 & 0.20 & 0.77 & 0.52 & 0.80 & 0.50 & $\mathrm{~N} / \mathrm{A}$ & 0.74 \\
\hline
\end{tabular}

Note: ' $\mu$ ' and ' $\tau$ ' are friction coefficient and shear stress, subscripts 'p' and 'ss' are peak and steady state, respectively. 


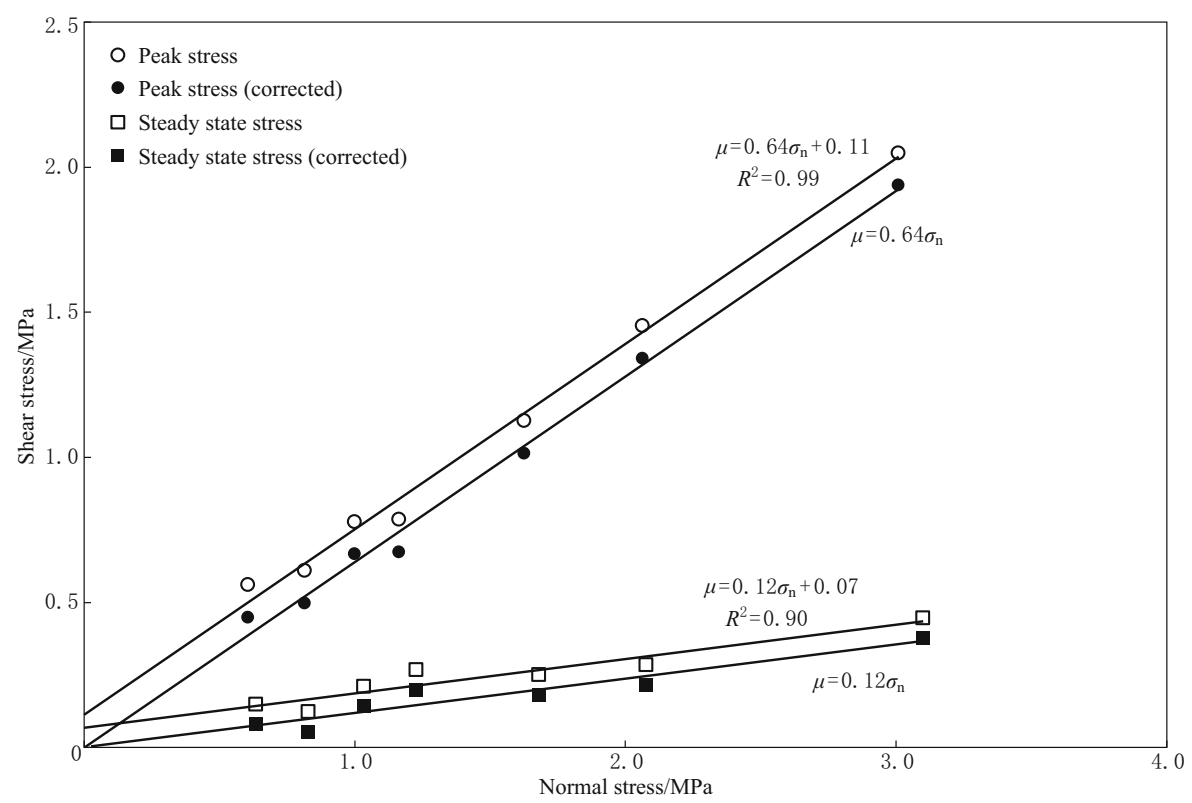

Figure 5 Shear stress plotted against the normal stress for seven gouge samples deformed dry at a slip rate of $1.3 \mathrm{~m} / \mathrm{s}$ for the peak friction in circles and for nearly the steady-state friction in squares. Circles denote shear stress and normal stress at the peak friction, averaged over fluctuations in the stresses during rotation of specimen. Squares show averages of measured shear stress and measured normal stress over the displacement from $D_{c}$, as determined by fitting equation (1), to the end of run. Small intercepts are attributed to Teflon friction. Filled symbols show shear stresses, corrected for Teflon friction, and normal stresses at the peak friction (circle) and at nearly the steady-state friction (square). Solid lines are least-squares fit to the data for peak friction and steady-state friction.

stress at the beginning of run when shear stress is about to rise. Also intercepts will remain on the shear stress versus normal stress plot after the correction, yielding apparent normal stress dependence on the friction coefficient. To overcome these two problems, we assumed that Teflon friction linearly increases from zero to peak friction (0.113 $\mathrm{MPa})$ and then decreases exponentially to steady-state value $(0.069 \mathrm{MPa})$ as described by equation (1) using $D_{\mathrm{c}}$ determined for gouge. Real Teflon friction may be slightly different from such a trend, but this would be the best we can. Shear stress was thus corrected for Teflon friction from measured shear stress by subtracting an idealized Teflon friction. This correction was made for all data shown in Figures 3 to 7 , except for those shown by open circles in Figure 5 that are used to determine Teflon friction. The correction for Teflon friction causes slight shift in the position of peak friction, but corrected positions are regarded as the peak friction in the data analyses.

Equation (1) fits the data in Figure 3 to yield friction parameters as shown in Figure 6. For gouge deformed dry at a slip rate of $1.3 \mathrm{~m} / \mathrm{s}$, both peak and steady friction coefficient values are nearly constant (ex- cept for one datum point for peak friction at the lowest normal) and agree with the result in Figure 5 (Figure $6 a)$. Note that the steady-state friction plotted in this figure and in Table 1 is determined by fitting equation (1) to experimental data corrected for Teflon friction; thus $\mu_{\mathrm{ss}}$ is slightly different from that shown in Figure 5 in which average shear stress and normal stress at displacement greater than $D_{\text {c }}$ are plotted. Whereas for gouge deformed dry at a normal stress of 1.0 MPa, friction coefficient at peak friction remains nearly the same at around 0.61 to 0.72 except for the lowest normal stress experiment (HVR 1491), close to the value for typical rocks at slow slip rates (cf. Byerlee, 1978), but friction coefficient at steady state markedly decreases with increasing slip rate. This decrease in steady-state friction can be described by the following equation, similar to equation (1):

$\mu_{\mathrm{ss}}(v)=\left.\mu_{\mathrm{ss}}\right|_{v=\infty}+\left(\left.\mu_{\mathrm{ss}}\right|_{v=0}-\left.\mu_{\mathrm{ss}}\right|_{v=\infty}\right) \exp \left(-v / V_{\mathrm{c}}\right)$,

where, $\mu_{\mathrm{ss}}(v)$ is steady state friction at velocity $v$, $\left.\mu_{\mathrm{ss}}\right|_{v=0}$ is $\mu_{\mathrm{ss}}$ at a slip rate of $0,\left.\mu_{\mathrm{ss}}\right|_{v=\infty}$ is $\mu_{\mathrm{ss}}$ at an infinitely large slip rate, and $V_{\mathrm{c}}$ is the critical weakening velocity specifying how rapidly $\mu_{\mathrm{ss}}$ decreases with 
increasing $v$. The solid line in Figure $6 \mathrm{~b}$ is a leastsquares fit to the experimental data using Kaleidagraph software; the fit with data is reasonably good with parameters, $\left.\mu_{\mathrm{ss}}\right|_{v=0}=0.81 \pm 0.05,\left.\quad \mu_{\mathrm{ss}}\right|_{v=\infty}=0.10 \pm 0.05$, $V_{\mathrm{c}}=0.39 \pm 0.10$. Steady-state friction at slow slip rates, for which abundant data have been collected, is plotted against slip rate on a logarithmic scale and is plotted very close to the origin in Figure 6. Equation (2) can not describe slip-rate dependence at slow slip rates and treat it as a constant $\left.\mu_{\mathrm{ss}}\right|_{v=0}$. It should be kept in mind that the equation is a conventional description of highvelocity frictional behavior.

Figure 7 shows slip weakening distance $\left(D_{\mathrm{c}}\right)$ plotted against the normal stress for gouge samples de- formed dry at a slip rate of $1.3 \mathrm{~m} / \mathrm{s}$ (Figure 7a) and against the slip rate for those deformed at a normal stress of 1.0 MPa (Figure 7b). Each datum point is obtained by least-squares fitting of equation (1) to the experimental results in Figure 3. $D_{\text {c }}$ decreases from 12.4 $\mathrm{m}$ at a normal stress of $0.61 \mathrm{MPa}$ to $1.9 \mathrm{~m}$ at $3.04 \mathrm{MPa}$, and it decreases from $13.8 \mathrm{~m}$ at a slip rate of $0.43 \mathrm{~m} / \mathrm{s}$ to $6.86 \mathrm{~m}$ at $1.30 \mathrm{~m} / \mathrm{s}$. The decrease in $D_{\mathrm{c}}$ with increasing normal stress $\sigma_{\mathrm{n}}$ or with increasing slip rate $v$ can be fit with a power law (solid lines in Figures $7 \mathrm{a}$ and $7 \mathrm{~b}$ ):

$$
D_{\mathrm{c}}\left(\sigma_{\mathrm{n}}, v\right)=A\left(\sigma_{\mathrm{n}}\right)^{-B} \cdot C(v)^{-D} \text {, }
$$

where $A, B, C$ and $D$ are fitting parameters. Individual
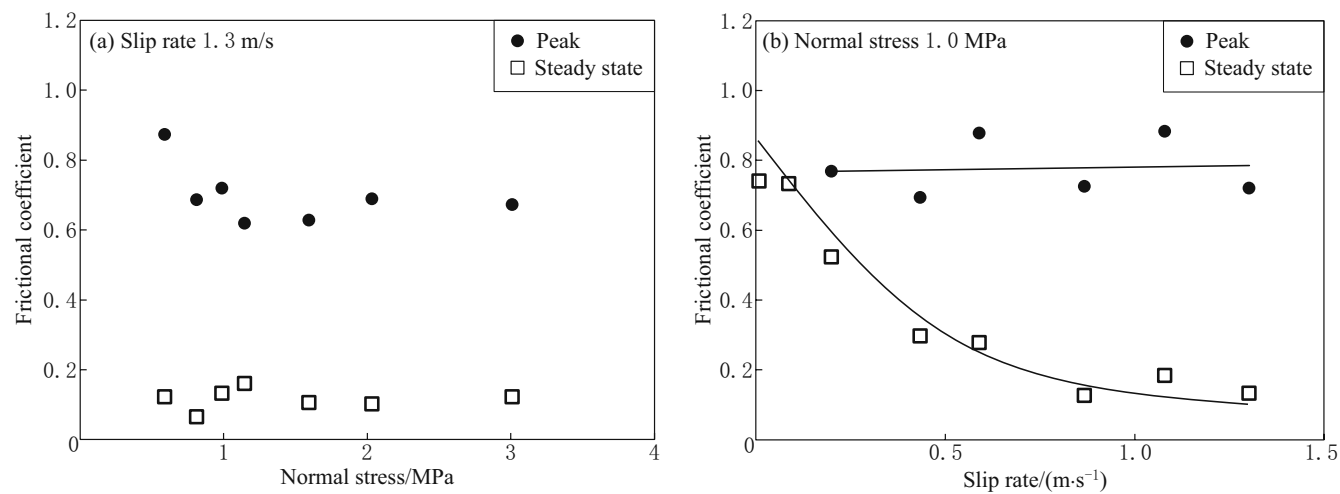

Figure 6 Frictional coefficient plotted against normal stress (a) and slip rate (b). Longmenshan fault gouge samples in (a) were deformed dry at a slip rate of $1.3 \mathrm{~m} / \mathrm{s}$ and those in (b) were deformed dry at a normal stress of 1.0 MPa. Peak frictional coefficient was determined from measured shear and normal stresses at the maximum shear stress after correction for Teflon friction, by taking averages over fluctuation during rotation of specimen. Whereas the steady-state frictional coefficients in the figures were determined by fitting equation (1) to the correction shear stress.
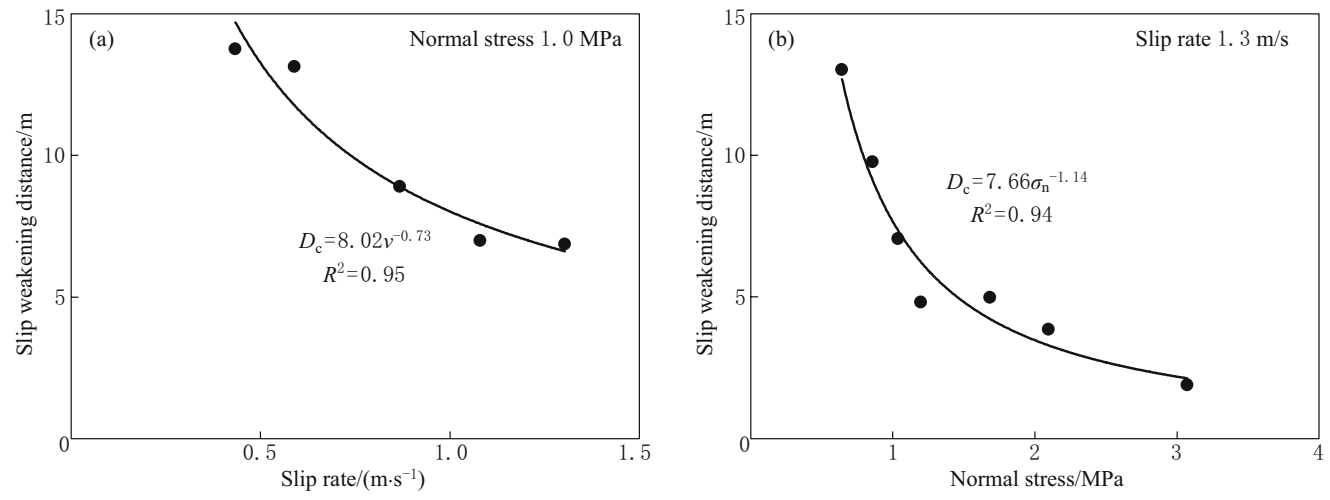

Figure 7 Slip-weakening distance $D_{\text {c }}$ plotted against slip rate for Longmenshan fault gouge samples deformed dry at a normal stress of 1.0 $\mathrm{MPa}$ (a) and against normal stress for gouge samples deformed dry at a slip rate of $1.3 \mathrm{~m} / \mathrm{s}(\mathrm{b})$. 
fit to each data set is shown as equations in Figure 7.

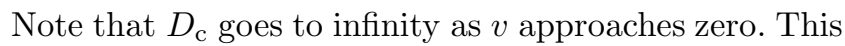
simply indicates that slip weakening that characterizes high-velocity frictional behavior does not occur at very slow slip rates.

The gray area underneath the slip weakening curve in Figure 4 give specific fracture energy $E_{\mathrm{G}}$ divided by normal stress $\sigma_{\mathrm{n}}$ (see Mizoguchi et al., 2007). Neglecting a small amount of displacement to peak friction and using the slip weakening law for post-peak behavior, one obtains

$$
\begin{gathered}
E_{\mathrm{G}}=-\left[\left(\mu_{\mathrm{p}}-\mu_{\mathrm{ss}}\right) / \ln 0.05\right] D_{\mathrm{c}} \sigma_{\mathrm{n}} \sim \\
0.334\left(\mu_{\mathrm{p}}-\mu_{\mathrm{ss}}\right) D_{\mathrm{c}} \sigma_{\mathrm{n}} .
\end{gathered}
$$

Steady-state is attained at infinite displacement for
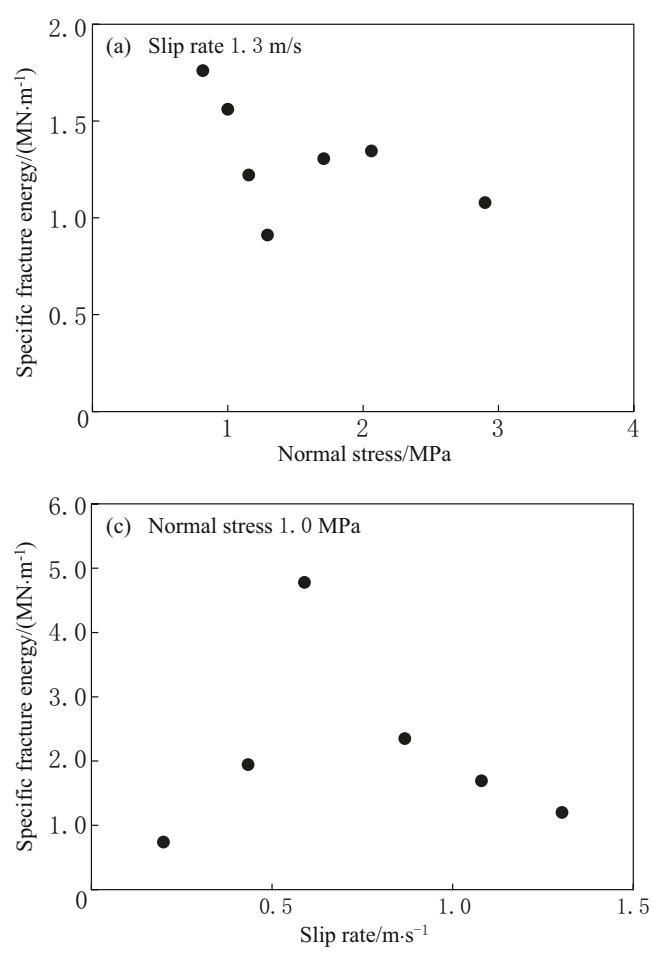

equation (1), so that integral for displacement was taken from zero at peak friction to infinite at steady-state to derive this equation. The specific fracture energy was determined using parameters in Table 1 (see the right column) and is plotted in Figure 8. As in previous studies (Mizoguchi et al., 2007; De Paola et al., 2011), $E_{\mathrm{G}}$ ranges from 1 to $4 \mathrm{MN} / \mathrm{m}$, tends to decrease with increasing normal stress (Figure 8a) and slip rate (Figure $8 \mathrm{c})$. $E_{\mathrm{G}}$ tends to increase slightly with increasing slip-weakening distance $D_{\mathrm{c}}$. However, this trend is not the same for $D_{\mathrm{c}}$ determined by changing normal stress at a slip rate of $1.3 \mathrm{~m} / \mathrm{s}$ (Figure $8 \mathrm{~b}$ ) and for $D_{\mathrm{c}}$ determined by changing slip rate at a normal stress of 1.0 $\mathrm{MPa}$ (Figure 8d). Thus we could not recognize a unique relationship between $E_{\mathrm{G}}$ and $D_{\mathrm{c}}$.
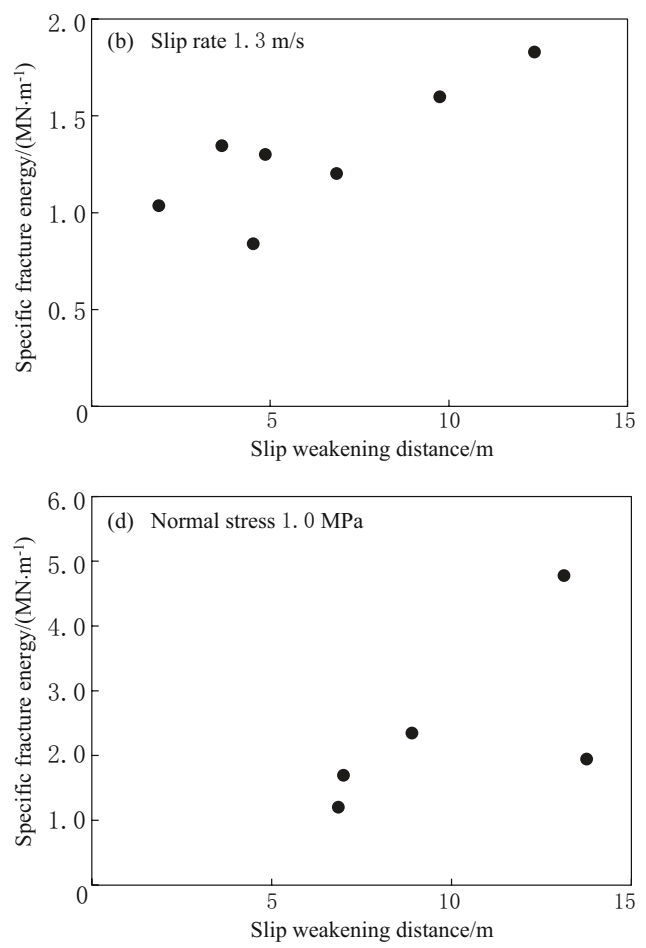

Figure 8 Specific fracture energy, $E_{\mathrm{G}}$, plotted against normal stress (a), slip weakening distance, $D_{\text {c }}$, as determined from tests at a slip rate of $1.3 \mathrm{~m} / \mathrm{s}(\mathrm{b})$, slip rate (c), and $D_{\mathrm{c}}$ from tests at a normal stress of 1.0 MPa (d).

\section{Microstructures and XRD analysis}

Detailed textural and material analyses of experimentally deformed gouge are in progress now. But we report here preliminary results for two specimens deformed at a subseismic slip rate of $0.01 \mathrm{~m} / \mathrm{s}$ (Figure 9) and at a slip rate of $0.43 \mathrm{~m} / \mathrm{s}$, almost seismic slip rate (Figure 10), in order to compare those with the textures recognized in Beichuan fault zone at Hongkou outcrop (Togo et al., 2011). Textures developed at intermediate and high slip rates are considerably different. Observe in Figures 2c and 2d that a shiny slickenside surface is developed only on the outer surface. The equivalent slip rate for this run was $1.3 \mathrm{~m} / \mathrm{s}$ and the local slip rate at the periphery of specimen is $1.96 \mathrm{~m} / \mathrm{s}$. Thus the boundary between shiny and grey-colored slickenside surfaces roughly corresponds to the local slip rate of about 

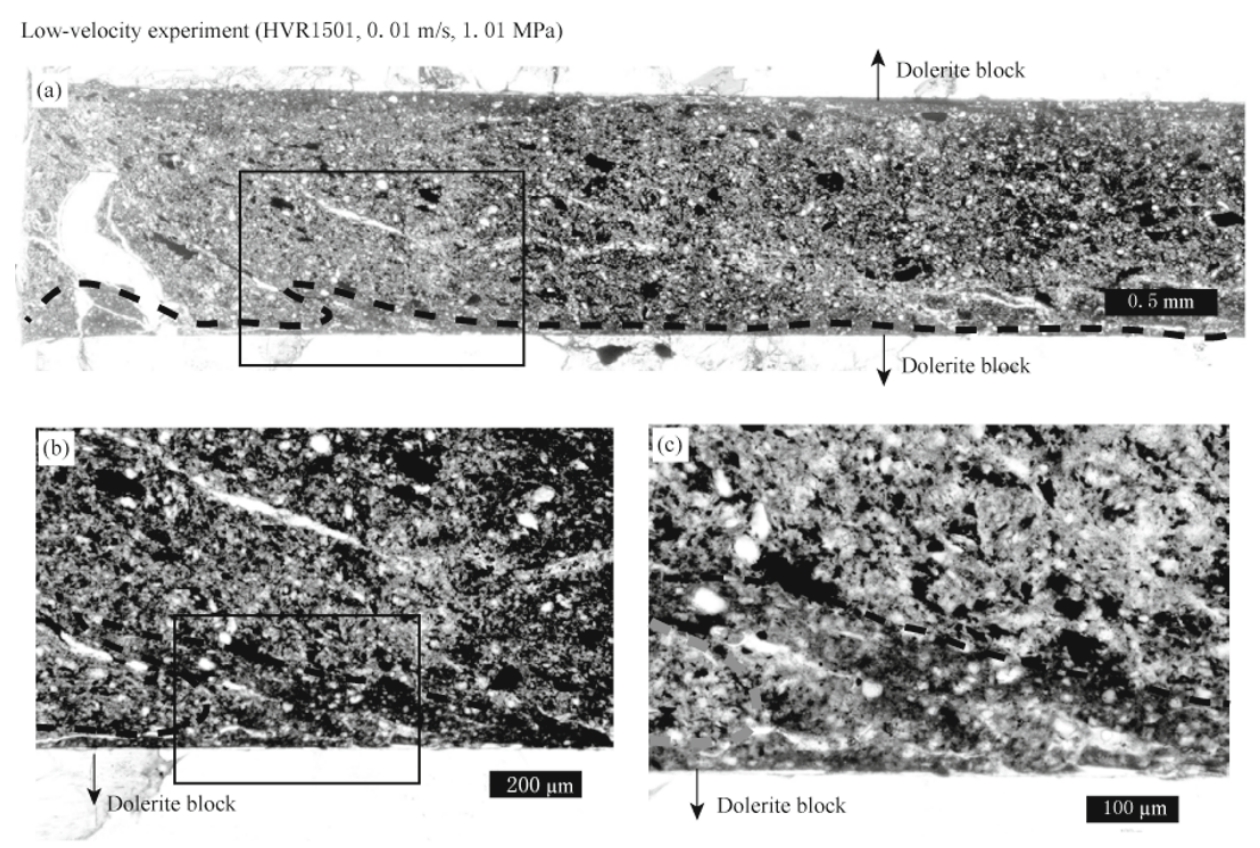

Figure 9 Photomicrographs of gouge deformed dry at a slip rate of $0.01 \mathrm{~m} / \mathrm{s}$ (subseismic slip rate) and at a normal stress of 1.01 MPa under plane-polarized light. (a) shows the bulk gouge zone between dolerite host blocks, (b) is a close-up of the framed portion in (a), and (c) is a close-up view of the rectangular frame in (b). Thin section was cut in a direction tangential to the circular cross-section and parallel to the cylindrical axis. Sense of shear is left-lateral as shown by a pair of arrows in (a) and the upper side was the rotary side.

$0.9 \mathrm{~m} / \mathrm{s}$. Another interesting feature in Figures $2 \mathrm{c}$ and $2 \mathrm{~d}$ is that slip zone developed within the gouge, close but not exactly at gouge/host rock interface. Thus mechanical behavior we report should reflect the gouge properties.

Figure 9 displays textures developed in gouge deformed at a slip rate of $0.01 \mathrm{~m} / \mathrm{s}$ (the subseismic slip rate, but the slowest slip rate in our experiments). The thin section was made in a tangential direction of circular slip direction and parallel to the cylinder axis, so that the marginal parts do not show textures in the shearing plane. The overall texture is characterized by weakly developed foliation due to preferred orientation of platy minerals (illite and chlorite according to XRD analyses below). The angle between the foliation and shear surface (gouge/host rock interface) varies from 20 to 30 degrees, which yields shear strain $\gamma$ of $1.2-2.4$ using an equation in Ramsay (1980) for simple shear. The shear strain is defined as displacement divided by shear zone thickness. Thus the above shear strain corresponds to a displacement of only a few millimeters; the initial compaction upon application of axial force is not included and this estimate is an order estimate. Deformation apparently has changed at a very initial stage of sliding from shearing of gouge to concentrated slip in narrow slip zones, close to gouge/host rock boundaries. Slip zones are developed close to both gouge/host rock interfaces in this case, with a sharp slip zone of a few tens of microns in width developed on the side of rotating block (upper side in Figure 9a). The slip zone on the stationary side is wider and less deformed (see clasts scattered in the zone) than that on the rotary side and exhibits wavy textures (Figures $9 \mathrm{~b}$ and 9c). Slip zones are characterized by dark color, but we have not identified material changes causing this change in color yet.

Figure 10 shows some preliminary photomicrographs of gouge deformed at a slip rate of $0.43 \mathrm{~m} / \mathrm{s}$ and at a normal stress of 1.0 MPa. Overall, deformed gouge consists of weakly-deformed, structureless gouge with a dark-color in the highly-sheared slip zone at the bottom of Figure 10a. In this run slip zone developed on the stationary side and no clear foliation is developed within the gouge zone. Granular minerals are scattered in weakly deformed gouge zone, but no such grains have survived in the slipping zone. Slip zone is foliated and its color changes from dark brown to almost black (compare the color in Figures 10a and 10b with the 

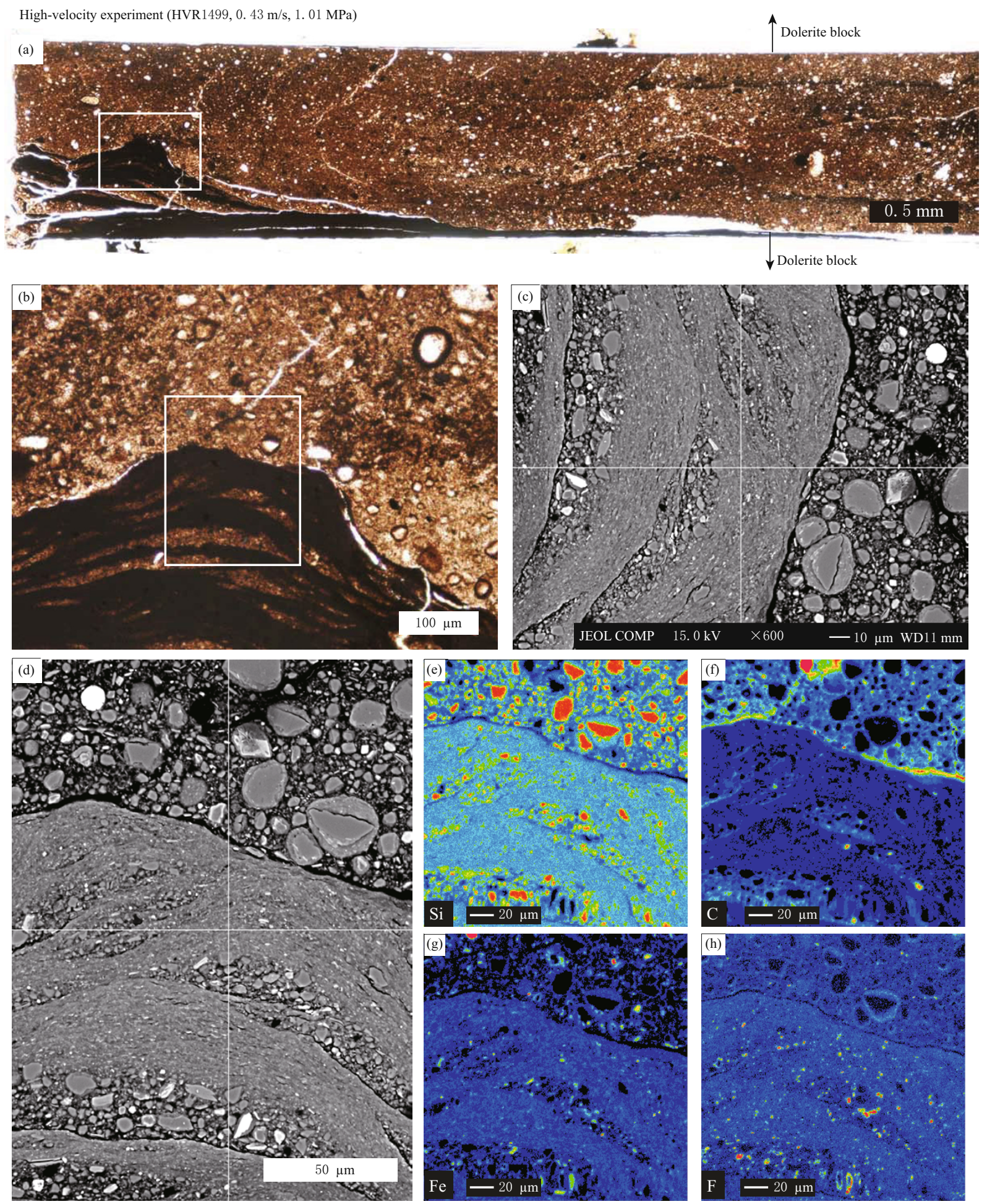

Figure 10 Microstructures developed in gouge deformed dry at a slip rate of $0.43 \mathrm{~m} / \mathrm{s}$, close to seismic slip rate, and at a normal stress of 1.01 MPa. (a) A photomicrograph of bulk gouge zone between dolerite host block with arrows indicating sense of shear. (b) A close-up of the framed portion in (a). (c) A SEM photomicrograph of the upper-right side of the framed portion in (b). (d) A SEM photomicrograph of the framed portion in (b). $(\mathrm{e}-\mathrm{h})$ EPMA element mapping for Si, C, Fe and F, respectively. Photomicrographs (a) and (b) were taken under plane-polarized light. Reddish and black colors in (e) to (f) indicate, respectively, higher and lower concentrations. 
light dark color in Figures 9b and 9c). Complex structures such as those developed on the lower-left corner of Figure 10a are likely to have formed due to a local overlapping of slip zones, since the slip zone is a single layer at other places. Close-up photomicrograph in Figure 10b exhibits folded-foliation. Further close-up SEM (scanning electron microscope) photomicrograph in Figure 10d reveals fine structures within overlapping slip zones; that is, dark brownish portions in Figure $10 \mathrm{~b}$ correspond to fine-grained portions in Figure 10d. Note also that the upper interfaces of the two slip zones are sharp, whereas the other sides changes gradually to corser-grained portions in Figure 10d. This asymmetric texture suggests that deformation localized towards one side of the slip zone during sliding (this ultimate narrow slip zone is not at the gouge/host rock boundary). Spherical textures around quartz clasts are developed next to the slip zone (Figures 10c and 10d) and those have identical features as "clay-clast aggregates" reported by Boutareaud et al. (2010).

We have conducted very preliminary chemical analysis on the slip zone, i.e., element analysis at the central point in Figure 10d and element mapping for $\mathrm{Si}$, $\mathrm{C}, \mathrm{Fe}$ and $\mathrm{F}$ in Figures $10 \mathrm{e}$ to $10 \mathrm{~h}$, respectively. The element analysis yielded: $\mathrm{C} 9.9 \%, \mathrm{SiO}_{2} 34.7 \%, \mathrm{TiO}_{2} 0.7 \%$, $\mathrm{Al}_{2} \mathrm{O}_{3}$ 19.7\%, $\mathrm{FeO} 5.4 \%, \mathrm{MgO} 2.2 \%, \mathrm{CaO} 0.6 \%, \mathrm{~K}_{2} \mathrm{O}$ $5.2 \%, \mathrm{Cl} 0.3 \%$ and $\mathrm{Au} 13.4 \%$. We did Au coating for the specimen, in stead of ordinary carbon coating, to analyze carbon content, and $\mathrm{Au}$ in the analysis came from the gold coating. Silica-rich parts in Figure 10e corresponds to quartz clasts or to coarse-grained portions. An interesting result is that the fine-grained slip zone is poor in carbon (see two dark layers in Figure 10f) even though carbon of almost $10 \%$ is contained in the zone. Oohashi et al. (2011) demonstrated that carbon oxidizes to form carbon dioxide in oxic environments. Out experiments were done in air and the carbon reduction in the slip zone may be due to the oxidation of carbonaceous materials. However, this oxidation depends on the oxygen fugacity and it is unclear if the same process operates in natural environments or not. Fine-grained slip zones are enriched in Fe (Figure $10 \mathrm{~g}$ ) and no trend was recognized in fluorine distribution (Figure 10h).

$\mathrm{X}$-ray diffraction (XRD) analyses did not reveal any notable mineralogical changes between gouge before experiments and on bulk gouge material deformed at a greater normal stress $(3.0 \mathrm{MPa})$ and at a higher slip rate $(1.3 \mathrm{~m} / \mathrm{s})$ than those for sample shown in Figure 11. Quartz, albite, dolomite, chlorite and illite were recognized in both samples.

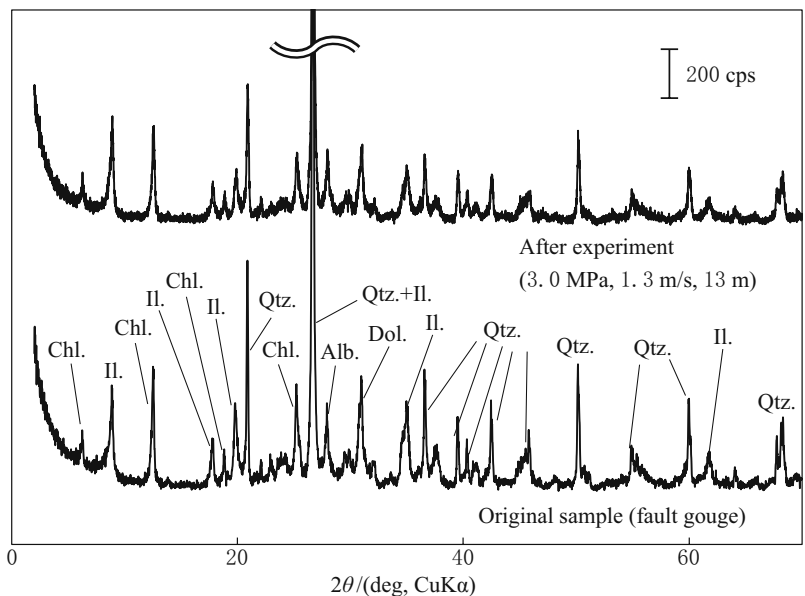

Figure 11 X-ray diffraction profiles of gouge deformed dry at a normal stress of $3.0 \mathrm{MPa}$ and at a slip rate of $1.3 \mathrm{~m} / \mathrm{s}$ (top) and of the original fault gouge sample of the Beichuan fault zone collected from Hongkou outcrop (bottom). Identified minerals are quartz (Qtz), albite (Alb), dolomite (Dol), chlorite (Chl) and illite (Il).

\section{Conclusions and discussion}

We have conducted high-velocity friction experiments on fault gouge from Hongkou outcrop of Beichuan fault, close to the coseismic fault during Wenchuan earthquake. Experiments were conducted at constan$\mathrm{t}$ slip rates to see overall frictional behaviors of clayey fault gouge at southwestern part of Longmenshan fault system, where coseismic displacement was very large (Togo et al., 2011). Main results are summarized as follows:

1) Fault gouge exhibits dramatic weakening at seismic slip rates and the steady-state frictional coefficient reduces as low as 0.1 to 0.2 at a slip rate of $1.3 \mathrm{~m} / \mathrm{s}$.

2) An empirical equation (1), proposed by Mizoguchi et al. (2007), describes observed slip-weakening very well. The behavior can be characterized by an exponential decay of friction from peak values $\mu_{\mathrm{p}}$ to steady-state values $\mu_{\mathrm{ss}}$ over a slip-weakening distance $D_{\mathrm{c}}$.

3) Dynamic weakening of faults during generation of large/great earthquakes is expressed quantitatively by exponential decrease of $\mu_{\mathrm{ss}}$ with slip rate $v$ and by a decrease of $D_{\mathrm{c}}$ as an inverse-power of $v$. Slip-weakening distance $D_{\text {c }}$ also decreases as an inverse power of normal stress. Thus, a fault loses its strength more rapidly and becomes more unstable towards greater depths.

4) Specific fracture energy $E_{\mathrm{G}}$ ranges from 1 to 4 $\mathrm{MN} / \mathrm{m}$ and tends to decrease slightly with increasing 
normal stress and slip rate. $E_{\mathrm{G}}$ also tends to increase with increasing slip-weakening distance $D_{\mathrm{c}}$, but there is no unique relationship between the two.

5) Gouge zone consists of weakly deformed zone and highly sheared slip zone. The latter has changed its color to dark brown to almost black. Locally the slip zone forms a duplex-like structure by overlapping of fine slip zones which is quite similar to those in Figures 10c and 10d of Togo et al. (2011). XRD analyses of bulk gouge has not revealed any changes in major constituent minerals. Element mapping has shown that carbon content is reduced in the slip zone. Shiny slickenside surface formed only at high slip rates.

Dramatic slip-weakening behavior of Longmenshan fault gouge is quite similar to those observed for other gouge materials (cf. Mizoguchi et al., 2007; Hirose and Bystricky, 2007; Han et al., 2007a, 2010; Brantut et al., 2008; De Paola et al., 2011; Di Toro et al., 2011). And yet exact weakening mechanism for gouge without frictional melting is still unclear; see comprehensive compilation of experimental data and discussions of weakening mechanisms in Di Toro et al. (2011). Flash weakening at asperity contacts (Rice, 2006) is a possible weakening mechanism at high slip rates. However, this mechanism does not work for nanoparticle gouges because of too short duration of contact time and Han et al. (2010, 2011) proposed rolling friction of nanoparticles as a weakening mechanism. But for the rolling mechanism, it is not perfectly clear why the rolling mechanism is not effective at low to intermediate slip rates where friction is not low. Present work cannot lead to a new and clear weakening mechanism for the weakening at high slip rates.

The high-velocity weakening of gouge is completely different from the slip-rate dependence of friction at slow slip rates (cf. data for the gouge collected at the same locality reported in Verberne et al., 2010). Focal depth of Wenchuan earthquake was $19 \mathrm{~km}$ deep (USGS location program data), so that rupture has to travel a long distance from a depth to propagate through the shallow incohesive fault zone, such as the Beichuan fault zone observed at Hongkou outcrop and in the WFSD drill holes. Fault begins to move abruptly following on earthquake nucleation and whether rupture stops or not at shallow depths is determined by high-velocity frictional properties of incohesive fault gouge, rather than velocity-weakening or velocity-strengthening property at slow slip rate. The initial peak friction $\mu_{\mathrm{p}}$ can be a barrier which may stop rupture propagation if the stress built-up at the rupture front cannot overcome it. Once peak friction is overcome, then dynamic fault motion can be promoted by marked slip-weakening as recognized in this study.

Recently, Faulkner et al. (2010) recognized that clay-rich fault gouge, containing water in a drained condition, does not exhibit large peak friction and proposed that earthquake rupture can propagate easily under such cases. Institute of Geology, China Earthquake Administration, has installed a new low to high-velocity rotary-shear friction apparatus equipped with a pressure vessel for conducting high-velocity friction experiments with controlled pore pressure. Present work will be extended to water-saturated conditions in the future.

Wet high-velocity experiments are important in comparison with temperature measurements in WFSD project. Two studies (Mori et al., 2010; Li et al., 2010b) recognized only very small temperature anomaly in WFSD-1 drill hole, suggesting that the frictional coefficient is far below 0.1 . We have shown that even dry gouge can yield frictional coefficient of 0.1 to 0.2 . This is still slightly larger than that implied by temperature measurements. Whether wet gouge have even smaller friction or not is a problem that we plan to study in the near future. Recent series of high-velocity experiments have shown that mineral decomposition can occur even during short duration of seismic fault motion (Han et al., 2007a, b; Hirose and Bystricky, 2007; Brantut et al., 2008, 2011; De Paola et al., 2011). Those workers demonstrated decomposition of calcite, dolomite, siderite, kaolinite, serpentinite and gypsum. Decomposition reactions are endothermic reactions and Brantut et al. (2011) have shown that a few to several tens of percents of frictional work can be consumed in this reaction. Thus, decomposition reactions in a fault zone, triggered by frictional heating, may affect the values of temperature measured after large events.

Specific fracture energy $E_{\mathrm{G}}$ is another quantity that may be compared with seismologically determined values although unfortunately the fracture energy is not estimated for the Wenchuan earthquake as yet. Values we obtained ( 1 to $4 \mathrm{MN} / \mathrm{m}$ ) are consistent with previous experimental results (Mizoguchi et al., 2007, 1-3 $\mathrm{MN} / \mathrm{m}$; De Paola et al., 2011, 0.5-5 MN/m). Those values are consistent with seismically determined values for the Kobe, Colfiorito and other earthquakes (Rice, 2006; Mizoguchi et al., 2007; De Paola et al., 2011). De Paola et al. (2011) recognized that $E_{\mathrm{G}}$ increases with increasing $D_{\mathrm{c}}$. We recognized a similar trend, but the relationship is not the same for $D_{\mathrm{c}}$ determined from velocity-changing experiments (Figure $8 \mathrm{~b}$ ) and for $D_{\mathrm{c}}$ 
determined from normal-stress changing experiments (Figure 8d). De Paola et al. (2011) used $D_{\mathrm{c}}$ determined only from normal-stress changing experiments, so that no unique relationship may exist between $E_{\mathrm{G}}$ and $D_{\mathrm{c}}$. Besides $E_{\mathrm{G}}$ will be affected substantially by the presence of pore water because the peak friction tends to be reduced (Faulkner et al., 2010). More work needs to be done on fracture energy in the future.

Black gouge was found in WFSD-1 core at the depth of about $590 \mathrm{~m}$ (Li et al., 2010a), and was characterized by content of clay minerals (smectite) and by high magnetic susceptibility. Experiments can also give insight on chemical-physical changes in the coseismic slip zone during Wenchuan earthquake. Siderite decomposition forms magnitite, changes gouge to very black in color and can also change dramatically magnetic susceptibility (Han et al., 2007b). Kaolinite decomposition created amorphous materials (Brantut et al., 2008) and smectite may grow fastest in amorphous materials during an interseismic period. Moreover, fault zone normally contains hydrous iron minerals and they can undergo series of reactions eventually forming magnetic minerals as confirmed by high-velocity experiments by Fukuchi et al. (2005). In this regard, color changes of our experimentally deformed gouge may be of interest since preliminary EPMA (electron probe microanalyzer) analysis indicated that the gouge contains about $5 \%$ of iron minerals. Thus, the color changes to dark brown or to almost black gouge observed in the slip zone (Figure 10) may be associated with changes in iron minerals. An integrated analysis of natural fault rocks and laboratory deformed ones may lead to more comprehensive understanding of the physical and chemical changes that can occur in fault zones during seismic fault motion.

Acknowledgements We sincerely thank anonymous reviewers for giving us many constructive comments and suggestions which substantially improved our paper. We also thank J. Ando, I. Katayama, K. Oohashi, T. Mitchell, K. Okazaki and M. Sawai for many stimulative discussions. Present work was supported by State Key Laboratory of Earthquake Dynamics (project No. LED2008A03) and Wenchuan Earthquake Fault Scientific Drilling Project (WFSD), by a Grant-in-Aid for JSPS fellows to the first author (T. Togo) and a Grant-in-Aid for young scientists (B) 201007605, and by a 2009 FGI Grant-in-Aid of Fukada Geological Institute.

\section{References}

Boutareaud S, Boullier A-M, Andreani M, Calugaru D-G, Beck P, Song S-R and Shimamoto T (2010). Clay-clast aggregates in gouges: a new textural evidence for seismic faulting. J Geophys Res 115: B02408, doi:10.1029/2008JB006254.

Brantut N, Schubnel A, Rouzaud J-N, Brunet F and Shimamoto T (2008). High velocity frictional properties of a clay-bearing fault gouge and implications for fault mechanics. J Geophys Res 113: B10401, doi:10.1029/2007JB005551.

Brantut N, Han R, Shimamoto T, Findling N and Schubnel A (2011). Fast slip with inhibited temperature rise due to mineral dehydration: evidence from experiments on gypsum. Geology 39: 59-62, doi:10.1130/G31424.1.

Byerlee J D (1978). Friction of rocks. Pure Appl Geophys 116: $615-626$.

De Paola N, Hirose T, Mitchell T, Di Toro G, Viti C and Shimamoto T (2011). Fault lubrication and earthquake propagation in thermally unstable rocks. Geology 39: 35-38, doi:10.1130/G31398.1.

Di Toro G, Han R, Hirose T, De Paola N, Nielsen S, Mizoguchi K, Ferri F, Cocco M and Shimamoto $\mathrm{T}$ (2011). Fault lubrication during earthquakes. Nature doi:10.1038/nature09838 471: 494-498.

Di Toro G, Hirose T, Nielsen S, Pennacchioni G and Shimamoto $T$ (2006). Natural and experimental evidence of melt lubrication of faults during earthquakes. Science 311: 647-649.

Faulkner D, Mitchell T M, Behnson J, Hirose T and Shimamoto T (2010). Stuck in mud? Earthquake rupture propagation along subduction mega-thrusts. In: Workshop on "Chemico-Physical Processes in Seismic Faults". Padova, 18-20 Nov., 2010.

Fukuchi T, Mizoguchi K and Shimamoto T (2005). Ferrimagnetic resonance signal produced by frictional heating: a new indicator of paleoseismicity. $J$ Geophys Res 110: B12404, doi:10.1029/2004JB003485.

Han R, Hirose T and Shimamoto T (2010). Strong velocity weakening and powder lubrication of simulated carbonate faults at seismic slip rate. $J$ Geophys Res 115: B03412, doi:10.1029/2008JB006136.

Han R, Hirose T, Shimamoto T, Lee Y and Ando J (2011). Granular nanoparticles lubricate faults during seismic slip. Geology (in press).

Han R, Shimamoto T, Ando J and Ree J-H (2007a). Seismic slip record in carbonate-bearing fault zones: An insight from high-velocity friction experiments on siderite gouge. Geology 35: 1131-1 134.

Han R, Shimamoto T, Hirose T, Ree J-H and Ando J (2007b). Ultra-low friction of carbonate faults caused by thermal decomposition. Science 316: 878-881.

Hirose T and Bystricky M (2007). Extreme dynamic weakening of faults during dehydration by coseis- 
mic shear heating. Geophys Res Lett 34: L143311, doi:10.1029/2007GL030049.

Hirose T and Shimamoto T (2005). Growth of molten zone as a mechanism of slip weakening of simulated faults in gabbro during frictional melting. $J$ Geophys Res 110: B05202, doi:10.1029/2004JB003207.

Lachenbruch A H (1980). Frictional heating, fluid pressure, and the resistance to fault motion. $J$ Geophys Res 85: 6097-6 112 .

Li H, Xu Z, Si J, Pei J, Li T, Huang Y and Wang H (2010a). Characteristics of the fault-related rocks, fault zone structures and the principal slip zone of the Wenchuan earthquake in WFSD drilling cores. American Geophysical Union, Fall Annual Meeting. San Francisco, T53E-02, Dec. 13-17, 2010.

Li Z, Peng H, Ma X and Jiang J (2010b). Temperature measurement and heat signature on the Longmen Shan fault zone associated with the May 12 Wenchuan earthquake, 2008, Sichuan, China. American Geophysical Union, Fall Annual Meeting. San Francisco, T51B-031, Dec. 13-17, 2010.

Lockner D A, Tanaka H, Ito H, Ikeda R, Omura K and Naka H (2009). Geometry of the Nojima fault at NojimaHirabayashi, Japan - I. A simple damage structure inferred from borehole core permeability. Pure Appl Geophys 166: 1649-1667, doi:10.1007/s00024-009-0515-0.

Mase C W and Smith L (1987). Effects of frictional heating on the thermal, hydrologic, and mechanical response of a fault. J Geophys Res 92: 6 249-6 272.

Mizoguchi K, Hirose T, Shimamoto T and Fukuyama E (2007). Reconstruction of seismic faulting by highvelocity friction experiments: An example of the 1995 Kobe earthquake. Geophys Res Lett 34: L01308, doi:10.1029/2006GL027931.

Mizoguchi K, Hirose T, Shimamoto T and Fukuyama E (2008). Internal structure and permeability of Nojima Fault, Southwest Japan. J Struct Geol 30: 513-524.

Mizoguchi K, Hirose T, Shimamoto T and Fukuyama E (2009). High-velocity frictional behavior and microstructure evolution of fault gouge obtained from Nojima fault, southwest Japan. Tectonophysics 471: 285-296.

Mori J J, Li H, Wang H, Kano Y, Pei J, Xu Z and Brodsky E E (2010). Temperature measurements in the WFSD-1 borehole following the 2008 Wenchuan earthquake $\left(M_{\mathrm{W}} 7.9\right)$. American Geophysical Union, Fall Annual Meeting. San Francisco, T53E-03, Dec. 13-17, 2010.

Nielsen S, Di Toro G, Hirose T and Shimamoto T (2008). Frictional melt and seismic slip. J Geophys Res 113: B01308, doi:10.1029/2007JB005122.

Noda H and Shimamoto T (2005). Thermal pressurization and slip-weakening distance of a fault: an example of the
Hanaore fault, Southwest Japan. Bull Seismol Soc Am 95: $1224-1233$, doi:10.1785/0120040089.

Oohashi K, Hirose T and Shimamoto T (2011). Shearinduced graphitization of carbonaceous materials during seismic fault motion: experiments and possible implications for fault mechanics. J Struct Geol 33: 1122-1 134.

Ramsay J G (1980). Shear zone geometry: a review. J Struct Geol 2: 101-110.

Rice J R (2006). Heating and weakening of faults during earthquake slip. J Geophys Res 111: B05311, doi:10.1029/2005JB004006.

Shimamoto T and Tsutsumi A (1994). A new rotary-shear high-speed frictional testing machine: its basic design and scope of research. Structural Geology (Journal of Tectonic Research Group of Japan) 39: 65-78 (in Japanese with English abstract).

Si J, Li H, Song S, Kuo L, Pei J and Wang H (2010). Clay mineral anomalies in WFSD drilling core and surface fault rocks and their significances. American Geophysical Union, Fall Annual Meeting. San Francisco, T51B-2044, Dec. 13-17, 2010.

Sibson R H (1973). Interactions between temperature and pore fluid pressure during an earthquake faulting and a mechanism for partial or total stress relief. Nature $\mathbf{2 4 3}$ : $66-68$.

Sone H and Shimamoto $\mathrm{T}$ (2009). Frictional resistance of faults during accelerating and decelerating earthquake slip. Nature Geosciences 2: 705-708, doi:10.1038/ bgei637 Letter.

Spray J G (1987). Artificial generation of pseudotachylyte using friction welding apparatus. J Struct Geol 9: 49-60.

Tinti E, Fukuyama E, Piatanesi A and Cocco M (2005). A kinematic source-time function compatible with earthquake dynamics. Bull Seismol Soc Am 95: 1211-1223, doi:10.1785/0120040177.

Togo T, Shimamoto T, Ma S L, Wen X Z and He H L (2011). Internal structure of Longmenshan fault zone at Hongkou outcrop, Sichuan, China, that caused the 2008 Wenchuan earthquake. Earthquake Science 23(3): 249265.

Tsutsumi A and Shimamoto T (1997). High-velocity frictional properties of gabbro. Geophys Res Lett 24: 699702 .

Verberne B A, He C and Spiers C (2010). Frictional properties of sedimentary rocks and natural fault gouge from the Longmen Shan fault zone, Sichuan, China. Bull Seismol Soc Am 100: 2767-2 790, doi:10.1785/012009287.

Wibberley C A J and Shimamoto T (2005). Earthquake slip weakening and asperities explained by thermal pressurization. Nature 436: 689-692, doi:10.1038/nature03901. 